injection to a total paraplegia at the level of T9 dermatome and persisted until the patient's death five years later. The packaging insert for methylene blue injection states that intraspinal injection is contraindicated.

S GERRARD

Pharmacy Department,

National Hospital for Nervous Diseases,
London WC1N 3BG

1 Evans JP, Keegan HR. FAMA 1960;174:856-9.
2 Schultz P, Schwarz GA. Arch Neurol 1970;22:240-4. Sharr MM, Weller RO, Brice JG. I Neurol Neurosurg Psychiatry 1978;41:384-6.

\section{Phenylbutazone overdose}

SIR,-I should like to comment on the report by Dr L F Prescott and others (25 October, p 1106) of a case of phenylbutazone overdose. They state that a case of phenylbutazone poisoning apparently had not been reported previously in the United Kingdom. I should like to draw their attention to such a report. ${ }^{1}$

Despite what Dr Prescott and his colleagues say about phenylbutazone being extensively metabolised and highly bound to plasma proteins, it is inaccurate to state that haemoperfusion is unlikely to enhance elimination significantly. In the case quoted, we were able to show a rapid reduction of blood phenylbutazone concentrations during haemoperfusion through columns of activated charcoal (Haemocol-Smith and Nephew Pharmaceutics Ltd). The use of haemoperfusion in this particular case was almost certainly life saving. The technique would seem to be indicated in severe cases of phenylbutazone overdose.

\section{John E STrong}

Holywood,

Co Down, BT18 9DB

${ }^{1}$ Strong JE, Wilson J, Douglas JD, Coppel DL.

\section{Primary biliary cirrhosis: an}

\section{epidemiological study}

SIR,-Dr David R Triger (20 September, p 772) and Dr W Stuart Hislop (18 October, p 1069) both record extensive experience with liver histology in their studies of primary biliary cirrhosis. Dr Triger says that "the diagnosis was supported [my italics] by histological findings in all patients who underwent biopsy, though in many cases the diagnoses were "consistent with" rather than "diagnostic of" primary biliary cirrhosis.

Dr Hislop writes, "In all cases the diagnosis was based on the well-described clinical features, and mitochondrial antibodies were uniformly present. Histological confirmation of the diagnosis was obtained in all cases"-two at necropsy. Dr Triger mentions that two elderly women were not biopsied as the procedure could not have been ethically justified. Of his 32 patients who had biopsies, histological specimens were obtained surgically on six occasions and percutaneously on 50 occasions. Only one patient (who had otherwise classical features of primary biliary cirrhosis) had no antimitochondrial antibodies.

These studies confirm the reliability of biochemical and serological data in the diagnosis of primary biliary cirrhosis. ${ }^{1}$ If the role of biopsy is "supportive" or "confirmatory" at best, and most often merely "consistent with," then the place of histology is surely best reserved for cases where the biochemical or the serological evidence is lacking despite careful follow-up and repeated measurement. ${ }^{2}$ If biopsy is no longer routinely necessary for diagnosis, does it contribute to management? These questions are of practical importance for those of us who wish to screen patients with rheumatic symptoms for evidence of hepatic abnormality; to identify patients with early and non-hepatic features of primary biliary cirrhosis; and to elucidate further the relationship between polymyalgia rheumatica, a common symptom complex with protean manifestations, and other diseases.

G F BATSTONE

Salisbury General Infirmary, Salisbury, Wilts SP2 7SX

J C ROBERTSON

M I D CAWLEY

M SATTAR

Southampton General Hospital,
Southampton, Hants.

1 Batstone GF, Robertson JC, Loebl WY. Br Med $\mathcal{f}$ $1979 ; \mathrm{i}: 125-6$. Robertson JC, Batstone GF, Loebl WY. Br Med F
1978;ii:1128.

\section{Endometriosis-continuing conundrum}

SIR,-Your leading article "Endometriosiscontinuing conundrum" (4 October, p 889) raises a number of interesting points. It is the experience of most gynaecologists with a major interest in infertility that this condition is far more common than previously held and if looked for is frequently diagnosed. A high index of suspicion, examination at the appropriate time of the menstrual cycle, including a rectal examination, and the use of laparoscopy all contribute to the increasing frequency with which it is diagnosed.

The dilemma that faces the gynaecologist, having diagnosed a minor degree of endometriosis, is whether per se it is a significant factor in causing the infertility. The association of endometriosis with disturbances of ovarian function needs to be established in carefully controlled investigations. However, the demonstration of endometriosis should lead the clinician into measuring more sensitive indicators of ovarian function, such as plasma progesterone levels in the luteal phase, rather than relying on basal temperature charts and secretory changes in endometrial biopsies. Once demonstrated, poor ovarian function can be rectified by treatment with antioestrogen ovarian stimulants such as clomiphene or tamoxifen.

Another possible mechanism of infertility in a woman with endometriosis is an adverse effect on survival of sperm in the pelvis. Indeed, few sperm have been found in pouch of Douglas aspirates in women with endometriosis (Hammerstein, personal communication). Survival of sperm in peritoneal fluid aspirated from the pouch of Douglas was measured by autocorrelation analysis of scattered laser light (with apparatus developed for this purpose within this department to measure sperm velocity). In aspirates obtained from the normal pelvis the survival and motility of sperm was enhanced compared with control sperm diluted in saline $(n=20)$. In subjects with a minor degree of endometriosis no adverse effects on sperm motility and velocity were observed $(n=8)$. However, in aspirates obtained from all women with more extensive endometriosis a major degree of inhibition of sperm survival and motility was observed $(n=6)$
This is an early ongoing study and more data are being collected. However, these preliminary data clearly indicate that a factor, as yet undetermined, appears to be released from significant areas of endometriosis into the peritoneal fluid, which has an adverse effect on sperm velocity and survival. It remains to be demonstrated whether medical treatment, with or without conservative surgery, can correct this apparent obstacle to fertility.

MaX ELSTEIN C I FILHO

Department of Obstetrics and Gynaecology, University Hospital of South Manchester, Manchester M20 8I.R

\section{Adverse reaction to bupivacaine}

SIR,-Reporting a case of neurotoxicity following the use of bupivacaine for intravenous regional analgesia (18 October, p 1043), Dr A $M$ Henderson quoted figures for peak plasma bupivacaine of $840 \mathrm{ng} / \mathrm{ml}$ four minutes after release of the tourniquet. ${ }^{1}$ These were the means of measurements of systemic venous plasma levels in five subjects. Another small study measured arterial blood concentrations and found peak levels between $4900 \mathrm{ng} / \mathrm{ml}$ and $11000 \mathrm{ng} / \mathrm{ml}$ one minute after tourniquet release, a similar technique having been used. ${ }^{2}$ Since plasma concentrations are generally 1.6 times those of whole blood ${ }^{3}$ there is an enormous discrepancy between the findings, which even a recognised higher concentration associated with arterial sampling ${ }^{3}$ cannot explain.

Where the concentrations of bupivacaine that may follow an intravenous regional block are not predictable then toxic sequelae, although rare, should not be totally unexpected. In order to increase the safety of this technique I would suggest, firstly, that an intravenous needle or cannula be placed in an unoccluded limb prior to any injection of local anaesthetic or tourniquet release. Secondly, since the effluent blood from the arm after tourniquet release carries considerable quantities of local anaesthetic for several minutes, ${ }^{25}$ reinflation of the tourniquet should be considered at the first signs of toxicity.

M FutTER

Department of Anaesthetics,

Southend Hospital,
Westcliff-on-Sea, Essex SSO ORY

1 Ware RJ, Caldwell J. Br $\mathcal{F}$ Anaesth 1976;48:1124-5. Watson RL, Marshali PR, Brown PW, Anesth Analg
(Cleve) 1970;49:300-4.

${ }^{3}$ Cleve) $1970 ; 49: 300-4$.
Reynolds FA. Br $\mathcal{F}$ Anaesth $1971 ; 43: 567-71$.

Moore DC, Bridenbaugh LD, Thompson GE. Anesth Analg (Cleve) 1978;57:42-53.

5 Tucker GT, Boas RA, Anesthesiology 1971 ;34:538-49.

\section{McIlroy-a suggestion}

SIR,-Dr Pallis and I always seem to be one jump behind McIlroy (save an episode last year when serendipity landed him in a geriatric bed under the care of my wife); but I am sure that Drs A J McGennis and M J Corry (1 November, $p$ 1217) would like to know that, since leaving Dublin in September, McIlroy has visited Glasgow-where, it seems, he was genuinely ill-and St Mary's, Praed Street, and Guy's Hospital in London.

The needs of brevity left us unable to give any details of McIlroy's numerous admissions in our original paper, but we can confirm that he had undergone psychiatric assessment at 